\title{
Folic acid supplementation before and during pregnancy in the Newborn Epigenetics STudy (NEST)
}

\author{
Cathrine Hoyo ${ }^{1 *}$, Amy P Murtha ${ }^{2 \dagger}$, Joellen M Schildkraut ${ }^{1 \dagger}$, Michele R Forman ${ }^{3 \dagger}$, Brian Calingaert ${ }^{1}$, \\ Wendy Demark-Wahnefried ${ }^{4+}$, Joanne Kurtzberg ${ }^{5}$, Randy L Jirtle $^{6}$, Susan K Murphy ${ }^{7 \dagger}$
}

\begin{abstract}
Background: Folic acid (FA) added to foods during fortification is $70-85 \%$ bioavailable compared to $50 \%$ of folate occurring naturally in foods. Thus, if FA supplements also are taken during pregnancy, both mother and fetus can be exposed to FA exceeding the Institute of Medicine's recommended tolerable upper limit (TUL) of 1,000 micrograms per day $(\mu \mathrm{g} / \mathrm{d})$ for adult pregnant women. The primary objective is to estimate the proportion of women taking folic acid (FA) doses exceeding the TUL before and during pregnancy, and to identify correlates of high FA use.
\end{abstract}

Methods: During 2005-2008, pre-pregnancy and pregnancy-related data on dietary supplementation were obtained by interviewing 539 pregnant women enrolled at two obstetrics-care facilities in Durham County, North Carolina.

Results: Before pregnancy, 51\% of women reported FA supplementation and $66 \%$ reported this supplementation during pregnancy. Before pregnancy, $11.9 \%(95 \% \mathrm{Cl}=9.2 \%-14.6 \%)$ of women reported supplementation with FA doses above the TUL of 1,000 $\mu \mathrm{g} /$ day, and a similar proportion reported this intake prenatally. Before pregnancy, Caucasian women were more likely to take FA doses above the TUL (OR $=2.99 ; 95 \%=1.28-7.00)$, compared to African American women, while women with chronic conditions were less likely to take FA doses above the TUL $(\mathrm{OR}=0.48 ; 95 \% \mathrm{Cl}=0.21-0.97)$. Compared to African American women, Caucasian women were also more likely to report FA intake in doses exceeding the TUL during pregnancy $(\mathrm{OR}=5.09 ; 95 \% \mathrm{Cl}=2.07-12.49)$.

Conclusions: Fifty-one percent of women reported some FA intake before and 66\% during pregnancy, respectively, and more than one in ten women took FA supplements in doses that exceeded the TUL. Caucasian women were more likely to report high FA intake. A study is ongoing to identify possible genetic and nongenotoxic effects of these high doses.

\section{Background}

Previous studies have demonstrated that daily folic acid (FA) supplementation during preconception lowers the risk of neural tube defects [1-4] and other adverse pregnancy outcomes such as low birth weight [5]. Because of this beneficial effect with no apparent adverse health outcomes in pregnancy, FA supplementation of approximately

\footnotetext{
* Correspondence: cathrine.hoyo@duke.edu

+ Contributed equally

'Department of Community and Family Medicine and Program of Cancer Detection, Prevention and Control, Duke University, PO Box 104006, Durham, NC 27710, USA

Full list of author information is available at the end of the article
}

400 micrograms per day $(\mu \mathrm{g} / \mathrm{d})$ from fortified foods, supplements, or both, was recommended for all women at risk of pregnancy $[3,6]$. To meet this recommendation, women take over-the-counter multivitamin supplements containing approximately $400 \mu \mathrm{g} / \mathrm{d}$ of FA [7]. Since clinical trials data showed that the full benefit of FA was conferred prior to conception and the national unintended pregnancy rate in the US is $49 \%$ [8], a more effective vehicle to reach women was pursued. In 1996, the Food and Drug Administration (FDA) approved population-wide fortification of milled grain at $140 \mu \mathrm{g} \mathrm{FA} / 100$ grams [9] to deliver an additional $100 \mu \mathrm{g} / \mathrm{d}$ of FA to the average adult diet [10].
C Biomed Central

(c) 2011 Hoyo et al; licensee BioMed Central Ltd. This is an Open Access article distributed under the terms of the Creative Commons Attribution License (http://creativecommons.org/licenses/by/2.0), which permits unrestricted use, distribution, and reproduction in any medium, provided the original work is properly cited. 
However, total folate intake exceeding the recommended limit has been reported among women of child-bearing age $[11,12]$.

Folic acid added to foods during fortification is 70-85\% bioavailable compared to $50 \%$ of folate occurring naturally in foods $[6,13]$. Thus, if FA supplements also are taken during pregnancy, both mother and fetus can be exposed to FA exceeding the Institute of Medicine's [6] recommended tolerable upper limit (TUL) of $1,000 \mu \mathrm{g} / \mathrm{d}$ for adult pregnant women. While folate is essential for supplying methyl groups for nucleotide synthesis and DNA replication, the effects of high FA doses are unknown. What is known is that since fortification began, American serosurveillance data indicate that circulating folate concentrations in serum and erythrocytes have increased 50-100\% in the general population $[14,15]$. While FA supplementation use before and during pregnancy has been monitored in numerous populations [16-21], the extent of high FA use in pregnant women is unknown. Herein, we contribute to the monitoring effort by estimating the proportion of pregnant women reporting intake of FA doses exceeding the TUL, and determining whether socio-demographic and lifestyle factors are associated with high use within the Newborn Epigenetics STudy (NEST).

\section{Methods}

\section{Study participants}

Study participants were recruited as part of the ongoing Newborn Epigenetics STudy (NEST), a prospective study of women and their children. NEST was designed to identify early exposures associated with stable epigenetic alterations in infants that may alter chronic disease susceptibility later in life. Trained recruiter/interviewers identified eligible participants by reviewing prenatal care appointment logs in Duke's Division of Maternal and Fetal Medicine at the beginning of each week, and eligible participants were invited to participate. Women were eligible if they were aged 18 years and older, pregnant and spoke English. To ensure access to labor and birth outcomes data, we excluded women who planned to receive obstetric care outside the Duke Obstetrics or Durham Regional Hospitals. The catchment area for Duke Maternal Fetal Medicine prenatal care clinic largely includes three contiguous counties in central North Carolina (NC); Durham, Orange and Wake. Women who met eligibility criteria were either consented and interviewed in-person, in consultation rooms during the visit, or were given the questionnaire to self-administer and mail back to the study office. If completed questionnaires were not received in the mail by the subsequent visit, another questionnaire was administered during a prenatal care visit. Interviewer-administered questionnaires took approximately 15 minutes to complete. At the end of the interview, all women were asked to provide contact information that included names, address and at least three telephone numbers to facilitate future contact. Because in utero exposure to cigarette smoke is associated with poor birth outcomes and may predict high FA use $[17,22]$, we targeted smokers to the extent possible, identifying them through medical records.

Gestational age at enrollment ranged from 19 to 42 weeks $($ mean $=38.1 ;$ sd $=2.5$ weeks $)$. By June 2008, 838 eligible women had been identified and 601 were enrolled (response rate of 71.7\%). Most enrollees (98.2\%) were successfully followed to delivery $(n=590)$. Children from these pregnancies are being followed to collect growth data once every two years. These analyses include 539 participants with complete questionnaire and medical records data. The study protocol was approved by the Duke University Institutional Review Board.

\section{Data Collection}

Domains for which information pertaining to the year before and the year during pregnancy was solicited included the following; demographic characteristics, health status, reproductive factors, lifestyle factors such as tobacco and alcohol use, anthropometric measurements before pregnancy and dietary supplementation. Although not used in the current analyses, diet was assessed using the 24-hour dietary recall (Nutritional Data Systems for Research, University of Minnesota). Medical records were also abstracted to obtain information on maternal morbidity and use of over-the-counter and prescribed medication. At delivery, we collected data related to labor, umbilical cord blood and birth outcomes, including birth weight.

\section{Folic acid supplementation}

To ascertain FA intake, participants were shown a list of dietary supplements that included multivitamins, multivitamins with additives such as herbs, FA/folacin, vitamin B6 (pyridoxine), vitamin B12 (cobalamin), and "other," and asked for Yes-No responses to the questions "In the 12 months before pregnancy, did you take [dietary supplement]?". To obtain folic acid intake during pregnancy, women were asked to respond to the question "Since you found out you were pregnant, did you take [dietary supplement]?" Supplement users were asked the brand name, the frequency of intake and trimester when intake started, if intake started during pregnancy. Study participants were unaware of the study hypothesis. The frequency and dose of FA intake before and during pregnancy was converted into daily $\mu \mathrm{g} /$ day FA intake using dosage information provided on the packet. Where specific brands were not recalled, a conservative value of $400 \mu \mathrm{g}$ was assigned.

\section{Statistical analyses}

Women were categorized as non-users (no supplementation), users within recommended range (intake 
$\leq 1,000 \mu \mathrm{g} / \mathrm{d}$ ), and users exceeding the TUL for adults (intake $>1,000 \mu \mathrm{g} / \mathrm{d}$ ). A dose of $\leq 1,000 \mu \mathrm{g} / \mathrm{d}$ was assigned to women reporting "over-the-counter daily multivitamin" as these supplements provide $\sim 400 \mu \mathrm{g} / \mathrm{d}$ of FA. Women taking "additional FA" providing $\sim 800 \mu \mathrm{g} / \mathrm{d}$ of FA, and those reporting intake of "prenatal vitamins only" which provide $\sim 600-1,000 \mu \mathrm{g} / \mathrm{d}$ of FA, were also included in the category of users within the recommended range. Doses exceeding $1,000 \mu \mathrm{g} / \mathrm{d}$ were assigned to women who reported intake of a combination of "prenatal vitamins" including those prescribed ( 600-1,000 $\mu \mathrm{g} / \mathrm{d})$ and "overthe-counter multivitamins" ( $400 \mu \mathrm{g} / \mathrm{d})$ of FA, and/or multivitamins with "additional FA" $(\sim 400 \mu \mathrm{g} / \mathrm{d})$. Total FA intake ranged from 0 to $>1,600 \mu \mathrm{g} / \mathrm{d}$.

FA supplementation before and during pregnancy was examined in relation to factors previously identified to predict any FA use including ethnicity [23], advanced maternal age [24], socioeconomic indicators (education, marital status and public or private health insurance) $[17,24]$ reproductive factors such as parity [17], use of cigarettes [17] and alcoholic or caffeinated beverages. We also evaluated FA supplementation in relation to factors not previously described, including participants' selfreported health indicators, a history of chronic illness (asthma, hypertension, depression, cardiovascular diseases, allergies, migraines, epilepsy, anxiety, cancer, gestational diabetes) and the use and type of assisted reproductive technology (ART) used in infertility treatments since infertility is also associated with FA use [17].

We estimated the proportions and 95\% confidence intervals (95\% CIs) of women reporting FA use exceeding the TUL, and examined correlates of use that could be used to target women for further study and possible intervention. Unconditional logistic regression models were used to estimate odds ratios (ORs) and 95\% CIs for the association between each correlate and FA supplementation. Nonusers were compared to users within recommended range $(\leq 1,000 \mu \mathrm{g} / \mathrm{d})$, and users exceeding the TUL $(>1,000 \mu \mathrm{g} / \mathrm{d})$, separately for use before and during pregnancy. Cigarette smoking was included in all statistical models except when we stratified by cigarette smoking. Independent effects were evaluated by mutual adjustment in parsimonious models. All statistical analyses were conducted in SAS v9.03 (SAS Institute Inc., Cary, NC).

\section{Results}

Characteristics presented in Table 1 suggest that study participants were similar to the general pregnant population in the three-county region of $\mathrm{NC}$ with respect to age, marital status and education of African Americans and Whites [25]. However, study participants were more likely to smoke or be exposed to environmental
Table 1 Characteristics of New Born Epigenetics STudy (NEST) Study Participants

\begin{tabular}{|c|c|c|}
\hline \multirow[t]{2}{*}{ Maternal Characteristic } & \multicolumn{2}{|c|}{$(n=539)$} \\
\hline & Number & (\%) \\
\hline \multicolumn{3}{|c|}{ Maternal age at beginning of pregnancy } \\
\hline$<25$ years & 166 & $(30.8)$ \\
\hline 25-34 years & 261 & $(48.4)$ \\
\hline $35-39$ & 91 & $(16.9)$ \\
\hline $40+$ & 20 & (3.7) \\
\hline Missing & 1 & $(0.2)$ \\
\hline \multicolumn{3}{|l|}{ Maternal ethnicity } \\
\hline African American & 258 & $(47.9)$ \\
\hline Caucasian & 246 & $(45.6)$ \\
\hline Asian/Native American/Latino & 26 & $(4.8)$ \\
\hline Missing & 9 & $(1.7)$ \\
\hline
\end{tabular}

Maternal marital status

Never married

154 (28.6)

Married

Living with partner

Divorced/separated

Missing

$241(44.7)$

$99(18.4)$

$44(8.2)$

$1(0.2)$

Maternal education

Less than high school

$63(11.7)$

High school graduate/GED

$46(27.1)$

Some college

College graduate

$45(27.1)$

$98 \quad(18.2)$

$86(16.0)$

$1(0.2)$

Missing

$250(46.4)$

$174(32.3)$

$115(21.3)$

Missing

$73(32.1)$

$113(21.0)$

$241(44.7)$

$12(2.2)$

Three or more

Missing

Cigarette smoking at interview

Non-smokers

$425(78.9)$

Smoker during pregnancy

$113(21.0)$

Exposure to secondhand smoke during index pregnancy

Yes

No

Missing

Pre-pregnancy body size

$<18 \mathrm{~kg} / \mathrm{m} 2$

$\geq 18 \mathrm{~g} / \mathrm{m} 2-<25 \mathrm{~kg} / \mathrm{m} 2$

$6(1.1)$

$164(30.4)$

$\geq 25 \mathrm{~kg} / \mathrm{m} 2-<30 \mathrm{~kg} / \mathrm{m} 2 \quad 96(17.8)$

$\geq 30 \mathrm{~kg} / \mathrm{m} 2$

Missing 
Table 1 Characteristics of New Born Epigenetics STudy (NEST) Study Participants (Continued)

\begin{tabular}{lrll}
\hline Therapeutic interventions & 135 & $(25.1)$ \\
Hormonal contraceptive us up to one year before & 17 & $(3.2)$ \\
interview & & \\
Use of assisted reproductive technology for index & & \\
pregnancy & 341 & $(63.3)$ \\
Co-morbid conditions at interview & 42 & $(7.8)$ \\
None & 27 & $(5.0)$ \\
Gestational diabetes & 88 & $(16.3)$ \\
Type 1 or Type 2 diabetes & 39 & $(7.2)$ \\
Asthma & 196 & $(36.4)$ \\
$*^{*}$ Other & & \\
**Any chronic disease & 265 & $(49.2)$ \\
Folic acid intake before pregnancy & 209 & $(38.8)$ \\
None & 64 & $(11.9)$ \\
Up to 1,000 $\mu \mathrm{g} /$ day & 1 & $(0.2)$ \\
More than $1,000 \mu \mathrm{g} /$ day & & \\
Missing & 182 & $(33.8)$ \\
Folic acid intake during pregnancy & 295 & $(54.7)$ \\
None & 61 & $(11.3)$ \\
Up to 1,000 $\mu \mathrm{g} /$ day & 1 & $(0.2)$ \\
\hline More than 1,000 $\mu \mathrm{g} /$ day & & \\
Missing &
\end{tabular}

*Other includes hypertension, depression, heart diseases, allergies, migraine headaches, epilepsy, anxiety, treated for cancer.

**Any chronic disease includes gestational diabetes, asthma, hypertension, depression, diabetes mellitus, heart diseases, allergies, migraine headaches, epilepsy, anxiety, treated for cancer.

tobacco smoke than those in the general three-county population.

\section{FA supplementation before and during pregnancy}

Overall, 51\% (95\%CI $=47-55 \%)$ of women reported some FA use before pregnancy. Recommended FA doses $(\leq 1,000 \mu \mathrm{g} / \mathrm{d})$ taken either as a multivitamin or a single dietary supplement were reported by $209 / 539$ or $39 \%$ (95\% CI $=35 \%-43 \%)$, and intake of doses exceeding the TUL for adults $(>1,000 \mu \mathrm{g} / \mathrm{d})$ was reported by $12 \%(95 \%$ CI $=9 \%-15 \%)$ of women before pregnancy [Table 1]. During pregnancy, some FA use was reported by $66 \%$ $(95 \% \mathrm{CI}=62 \%-70 \%)$ of women. FA intake within recommended doses of $\leq 1,000 \mu \mathrm{g} / \mathrm{d}$ was reported by $295 / 539$ or $55 \%(95 \% \mathrm{CI}=51-59 \%)$, and intake of doses exceeding the TUL for adults of $>1,000 \mu \mathrm{g} / \mathrm{d}$ was reported by $11 \%(95 \% \mathrm{CI}=8 \%-14 \%)$ of women. Because we targeted smokers, we also evaluated whether FA use exceeding the TUL varied by smoking status. We found no statistically significant differences in FA use by smoking status as $6 \%(95 \% \mathrm{CI}=2 \%-11 \%)$ of smokers and $13 \%(95 \% \mathrm{CI}=$ $10 \%-17 \%)$ of non-smokers reported FA intake $\geq 1,000$ $\mu \mathrm{g} / \mathrm{d}$ before pregnancy $(\mathrm{p}$-value $=0.11)($ data not shown). During pregnancy, the proportion of women reporting FA use exceeding TUL for adults was also similar in smokers $12 \%(95 \% \mathrm{CI}=6 \%-17 \%)$ and nonsmokers $11 \%(95 \% \mathrm{CI}=8 \%-14 \%)(\mathrm{p}$-value $=0.81)$.

\section{Correlates of dietary folic acid supplementation FA supplementation before pregnancy}

Compared to non-users, FA intake exceeding 1,000 $\mu \mathrm{g} / \mathrm{d}$ before pregnancy was reported more frequently by women who were aged $>35$ years $(\mathrm{OR}=5.5,95 \% \mathrm{CI}=$ 2.3-13.2), married or living with partner $(\mathrm{OR}=3.5,95 \%$ $\mathrm{CI}=1.9-6.6)$, privately insured $(\mathrm{OR}=4.7,95 \% \mathrm{CI}=$ 2.5-8.9), Caucasian $(\mathrm{OR}=3.6,95 \% \mathrm{CI}=2.0-6.5)$, and women with a college or higher education $(\mathrm{OR}=8.5,95 \%$ $\mathrm{CI}=2.0-36.3)$. Smokers $(\mathrm{OR}=0.4,95 \% \mathrm{CI}=0.2-0.8)$, those exposed to second hand smoke $(\mathrm{OR}=0.4,95 \% \mathrm{CI}=$ $0.2-0.9)$ and those reporting any chronic disease (OR = $0.4,95 \% \mathrm{CI}=0.2-0.8$ ), were less likely to report FA intake exceeding the TUL. Mutual adjustment of these factors revealed some attenuation of these effects as FA intake exceeding the TUL remained significantly more likely to be reported by Caucasian women (adjusted OR $=3.0$, $95 \% \mathrm{CI}=1.3-7.0$ ), and less likely by women reporting at least one chronic condition during pregnancy (adjusted $\mathrm{OR}=0.5,95 \% \mathrm{CI}=0.2-1.0$ ). The direction of the association between high FA intake and advanced maternal age (adjusted $\mathrm{OR}=2.2,95 \% \mathrm{CI}=0.8-6.4)$, being married or living with a partner (adjusted $\mathrm{OR}=1.9,95 \% \mathrm{CI}=0.9$ $4.0)$, and having a college or higher education $(\mathrm{OR}=7.6$, $95 \% \mathrm{CI}=0.9-65.2)$ were maintained in multivariate analyses, although the magnitude of associations was attenuated [Table 2]. The direction and magnitude of these associations was similar among FA users exceeding the TUL and those whose intake was within recommended doses, and among smokers.

\section{FA supplementation during pregnancy}

Table 2 also shows that FA use exceeding 1,000 $\mu \mathrm{g} / \mathrm{d}$ during pregnancy was associated with maternal age $>35$ years $(\mathrm{OR}=2.4,95 \% \mathrm{CI}=1.0-5.7)$, Caucasian race/ethnicity $(\mathrm{OR}$ $=6.4 ; 95 \% \mathrm{CI}=3.4-12.2)$, being married $(\mathrm{OR}=2.2,95 \% \mathrm{CI}$ $=1.2-4.0)$, having a college or higher education $(\mathrm{OR}=2.7$, $95 \% \mathrm{CI}=1.0-7.0)$, being privately insured $(\mathrm{OR}=3.0,95 \%$ $\mathrm{CI}=1.5-5.8)$, and having had three or more live births $(\mathrm{OR}=0.4,95 \% \mathrm{CI}=0.2-0.8)$. After simultaneous adjustment for each factor, being Caucasian $(\mathrm{OR}=5.1,95 \%=$ 2.1-12.5) remained associated with intake of FA doses exceeding the TUL. Interestingly, being Caucasian was also associated with FA use within recommended ranges $(\mathrm{OR}=4.7,95 \%=2.6-8.5)$. Similar patterns of association emerged in smokers and in non-smokers.

Five percent of women reported FA supplementation $\geq 1,000 \mu \mathrm{g} / \mathrm{d}$ both before pregnancy and during pregnancy, and $75 \%$ were Caucasians with a college or higher education. 
Table $2 *$ Adjusted odds ratios (ORs) and $95 \%$ confidence intervals for the association between maternal characteristics and folic acid supplement before and during pregnancy

\begin{tabular}{|c|c|c|c|c|c|c|c|c|c|c|}
\hline \multirow[b]{2}{*}{ Characteristic } & \multicolumn{5}{|c|}{ FOLIC-ACID USE BEFORE PREGNANCY } & \multicolumn{5}{|c|}{ FOLIC-ACID USE DURING PREGNANCY } \\
\hline & $\begin{array}{l}\text { None } \mathrm{n} \\
=265\end{array}$ & $\begin{array}{l}<1,000 \\
\mu \mathrm{g} / \text { day } \\
\mathrm{n}=209\end{array}$ & $\begin{array}{l}\geq 1,000 \\
\mu \mathrm{g} / \text { day } \\
\mathrm{n}=64\end{array}$ & $\begin{array}{l}<1,000 \mu \mathrm{g} / \text { day } \\
\mathrm{OR}(95 \% \mathrm{Cl})\end{array}$ & $\begin{array}{l}\geq 1,000 \mu \mathrm{g} / \text { day } \\
\mathrm{OR}(95 \% \mathrm{Cl})\end{array}$ & $\begin{array}{l}\text { None } \mathrm{n} \\
=182\end{array}$ & $\begin{array}{l}<1,000 \mu \mathrm{g} / \text { day } \\
\mathrm{n}=295\end{array}$ & $\begin{array}{l}\geq 1,000 \mu \mathrm{g} / \\
\text { day } \mathrm{n}=62\end{array}$ & $\begin{array}{l}<1,000 \mu \mathrm{g} / \text { day } \\
\mathrm{OR}(95 \% \mathrm{Cl})\end{array}$ & $\begin{array}{l}\geq 1,000 \mu \mathrm{g} / \text { day } \\
\text { OR(95\%Cl) }\end{array}$ \\
\hline \multicolumn{11}{|c|}{$\begin{array}{l}\text { Maternal age at beginning of } \\
\text { pregnancy }\end{array}$} \\
\hline$<25$ years & 107 & 50 & 9 & 1.00 & 1.00 & 69 & 81 & 16 & 1.00 & 1.00 \\
\hline 25-34 years & 117 & 107 & 36 & $1.42(0.83-2.43)$ & $2.21(0.87-5.59)$ & 90 & 137 & 33 & $0.65(0.37-1.14)$ & $0.82(0.32-2.09)$ \\
\hline $35+$ & 41 & 51 & 19 & $1.31(0.68-2.54)$ & $2.20(0.76-6.42)$ & 22 & 77 & 12 & $1.60(0.77-3.33)$ & $1.49(0.44-5.06)$ \\
\hline \multicolumn{11}{|l|}{ Maternal ethnicity } \\
\hline African American & 165 & 71 & 21 & 1.00 & 1.00 & 137 & 98 & 22 & 1.00 & 1.00 \\
\hline Caucasian & 85 & 122 & 39 & $2.00(1.18-3.38)$ & $2.99(1.28-7.00)$ & 35 & 175 & 36 & $4.70(2.60-8.51)$ & $5.09(2.07-12.49)$ \\
\hline Asian/Native American & 12 & 12 & 2 & $1.04(0.39-2.80)$ & $0.87(0.15-5.00)$ & 8 & 16 & 2 & $1.10(0.40-3.01)$ & $0.77(0.13-4.52)$ \\
\hline \multicolumn{11}{|l|}{ Maternal marital status } \\
\hline Married or live with partner & 127 & 164 & 49 & $2.66(1.59-4.45)$ & $1.92(0.86-4.33)$ & 84 & 215 & 40 & $1.44(0.87-2.41)$ & $1.10(0.46-2.69)$ \\
\hline $\begin{array}{l}\text { Not married or living with } \\
\text { partner }\end{array}$ & 137 & 45 & 15 & 1.00 & 1.00 & 97 & 80 & 21 & 1.00 & 1.00 \\
\hline \multicolumn{11}{|l|}{ Maternal education } \\
\hline Less than high school & 41 & 19 & 2 & 1.00 & 1.00 & 26 & 31 & 6 & 1.00 & 1.00 \\
\hline High school graduate/GED & 97 & 39 & 10 & $1.12(0.47-2.65)$ & $3.40(0.37-31.1)$ & 78 & 61 & 7 & $0.85(0.38-1.93)$ & $0.62(0.13-3.01)$ \\
\hline $\begin{array}{l}\text { College graduate/Graduate } \\
\text { school Some college }\end{array}$ & 126 & 151 & 52 & $1.70(0.74-3.90)$ & $7.60(0.89-65.2)$ & 77 & 203 & 48 & $1.69(0.74-3.86)$ & $2.37(0.53-10.6)$ \\
\hline \multicolumn{11}{|l|}{ Second hand smoke } \\
\hline Yes & 98 & 47 & 13 & $0.63(0.36-1.12)$ & $1.42(0.57-3.50)$ & 73 & 69 & 16 & $0.48(0.27-0.84)$ & $0.54(0.21-1.38)$ \\
\hline No & 165 & 159 & 50 & 1.00 & 1.00 & 107 & 222 & 45 & 1.00 & \\
\hline \multicolumn{11}{|l|}{ Parity } \\
\hline One & 80 & 71 & 22 & 1.00 & 1.00 & 45 & 103 & 25 & 1.00 & 1.00 \\
\hline Two & 51 & 46 & 16 & $1.02(0.55-1.90)$ & $1.63(0.65-4.09)$ & 36 & 63 & 14 & $0.90(0.46-1.78)$ & $0.73(0.26-2.04)$ \\
\hline Three or more & 126 & 89 & 25 & $1.07(0.62-1.85)$ & $1.74(0.69-4.04)$ & 94 & 126 & 20 & $1.12(0.61-2.04)$ & $0.65(0.26-1.62)$ \\
\hline \multicolumn{11}{|l|}{$\begin{array}{l}\text { Pre-pregnancy body mass } \\
\text { index }\end{array}$} \\
\hline$<25 \mathrm{~kg} / \mathrm{m}^{2}$ & 76 & 67 & 27 & 1.00 & 1.00 & 46 & 101 & 24 & 1.00 & 1.00 \\
\hline$\geq 25 \mathrm{~kg} / \mathrm{m}^{2}$ & 155 & 114 & 32 & $1.07(0.67-1.71)$ & $0.79(0.39-1.59)$ & 108 & 164 & 29 & $0.83(0.50-1.39)$ & $0.46(0.20-1.05)$ \\
\hline \multicolumn{11}{|l|}{ Co-morbid conditions } \\
\hline Any chronic disease & 105 & 77 & 13 & $0.83(0.52-1.31)$ & $0.45(0.21-0.97)$ & 70 & 101 & 24 & $0.92(0.56-1.50)$ & $0.95(0.43-2.12)$ \\
\hline None & 159 & 131 & 51 & 1.00 & 1.00 & 110 & 194 & 37 & 1.00 & 1.00 \\
\hline \multicolumn{11}{|l|}{$\begin{array}{l}\text { Cigarette smoking during } \\
\text { pregnancy }\end{array}$} \\
\hline Yes & 69 & 36 & 7 & $0.82(0.43-1.56)$ & $0.40(0.12-1.28)$ & 36 & 64 & 13 & $2.37(1.21-4.65)$ & $1.39(0.46-4.19)$ \\
\hline No & 195 & 173 & 57 & 1.00 & 1.00 & 145 & 231 & 48 & 1.00 & 1.00 \\
\hline
\end{tabular}

*Odds ratios are mutually adjusted, referents are women reporting no supplement use. 


\section{Discussion}

Our key findings were that overall, $51 \%$ of women reported some FA intake before pregnancy and $66 \%$ reported the same during pregnancy. In addition, more than $10 \%$ of women reported daily FA supplementation exceeding the TUL before or during pregnancy. Notably, $5 \%$ of the women reported taking FA exceeding the TUL, both before and during pregnancy. FA intake exceeding TUL was most frequently reported by Caucasian women, and least frequently by those reporting at least one morbid condition. Borderline associations were also found with advanced maternal age and having a college or higher education. Recently, data from the National Health and Nutrition Examination Survey estimated that in women of childbearing age, $\sim 1 \%$ of women are exposed to FA doses exceeding 1,000 $\mu \mathrm{g} / \mathrm{d}$ from fortified food alone, and $26 \%$ report FA intake in doses exceeding the recommended $400 \mu \mathrm{g} / \mathrm{d}$ [23].

Median folate intake among women of child-bearing age in the US is $450 \mu \mathrm{g} / \mathrm{d}$ (range 154-2,800ug/d) and approximately $75 \%$ is contributed by FA $[10,23]$. Because synthetic folate, or FA, is $70-85 \%$ bioavailable compared to $50 \%$ of folate occurring naturally in food [6], these findings suggest a sizable subpopulation of mothers and fetuses may be exposed to what some describe as supraphysiological folate levels [26]. To date, the adverse health effects of such exposure are unknown in humans. However, circulating folate levels have approximately doubled in the last decade $[14,15]$. Some large observational and randomized clinical trial data $[27,28]$, but not all [29], suggest an increased risk of twin pregnancies in women with high circulating serum folate levels during pregnancy, independent of age and fertility. High FA intake early in pregnancy also has been linked to an increase in the frequency of the methylenetetrahydrofolate reductase (MTHFR) 677Tallele in the fetus [30,31]. Carrying this genetic variant has been associated with chronic conditions including depression, schizophrenia, bipolar disorder, asthma, and wheezing later in life [32-35]. Conversely, peri-conceptional FA intake $>400 \mu \mathrm{g} / \mathrm{d}$ was recently associated with improvements in cytosine-guanine (CpG) methylation at the insulin-like growth factor (IGF2) differentially methylated region (DMR) that regulates $I G F 2$ imprinting in children [36]. Loss of imprinting at this IGF2 DMR has been associated with a higher risk of overgrowth disorders in childhood [37] and colon cancer in adulthood [38]. Our findings would suggest that a sizable proportion of pregnant women and their fetuses are exposed to FA exceeding the TUL. Because the original TUL was based on the potential for excessive folate to mask vitamin B12 deficiency (rare in pregnant women), and there are potential epigenetic benefits of FA supplementation, it is prudent to continue to monitor dosages of FA exposure in the population, and study its possible effects towards the goal of establishing limits based on the genotoxic and non-genotoxic effects.

The estimate of $66 \%$ FA use during pregnancy in our study is consistent with previous reports among pregnant women in the US $[39,40]$ and other developed countries [29]. While the use of FA before pregnancy by $51 \%$ of women in the current study is higher than reports from previous studies of non-pregnant women in the US, which ranged from $27 \%$ in Arkansas to $44 \%$ in Rhode Island [39-44], it is similar to the $53 \%$ recently reported in an American six-site, hospitalbased study [16]. The significance of the inverse association between morbidity and FA exceeding the TUL is unclear although it may reflect increased counseling of FA users since such conditions require frequent contact with health care providers. Associations between Caucasian race/ethnicity and high FA intake are consistent with previous reports where any FA supplementation was evaluated $[39,45]$, and may reflect increased knowledge of B vitamin pharmacokinetics where excess intake may not be viewed as harmful. More probable is that Caucasian race/ethnicity and perhaps advanced maternal age and higher education represent greater wherewithal to access supplemental FA, suggesting a need for population-wide re-education on currently recommended FA use.

While the design is hospital-based, the distribution of demographic characteristics in this population is similar to that of the three-county region from which study participants largely arose $[25,46]$ and are consistent with those reported by previous studies evaluating FA intake in the US and elsewhere $[18,44,47,48]$. A limitation of our findings is that we were unable to evaluate the potential effect of unplanned pregnancy in the association between potential correlates and FA supplementation. It is possible that FA intake exceeding TUL, during the prenatal period may be influenced by a desire to compensate for non-FA intake during peri-conception. The interpretation of these findings is also limited by our inability to prospectively monitor dosages of FA before and during pregnancy. Therefore, confirmation of these findings in larger studies will require active follow-up and validation of self-reports with serial measurement of maternal erythrocyte folate concentrations and dietary assessments. Meanwhile, prudence dictates that recommended FA doses are used by all women planning a pregnancy.

\section{Conclusions}

In summary, while the FDA goal of consuming at least $400 \mu \mathrm{g} / \mathrm{d}$ of FA pre-conceptionally has been achieved by $50 \%$ of women of childbearing age, more than one-tenth of pregnant women consume daily doses that exceed the 
TUL with unknown effects to humans. The use of FA exceeding the TUL was associated with Caucasian race/ ethnicity, advanced maternal age and a college or higher education. This study is part of a larger effort to characterize the role of early exposures on genetic and epigenetic perturbations in humans.

\section{Acknowledgements \\ We thank the parents and children of the Newborn Epigenetics STudy, research nurse Tammy Bishop, and research assistants Stacy Murray, Carole Grenier, Darby Kroyer, Natasha Duggan, and Suba Narasimhan for tracing enrolled participants; data manager Francine Overcash for statistical assistance, and the obstetrics faculty and staff at Duke University and Durham Regional Hospitals, Durham, NC. \\ This work was supported by the US National Institutes of Health R21ES014947, R01ES016772, K01CA104517 and the O'Keefe Foundation.}

\section{Author details}

'Department of Community and Family Medicine and Program of Cancer Detection, Prevention and Control, Duke University, PO Box 104006, Durham, NC 27710, USA. '2Department of Obstetrics and Gynecology, Division of Maternal-Fetal Medicine, Duke University, 4022 Hospital South, Durham, NC 27710, USA. ${ }^{3}$ Department of Epidemiology, MD Anderson Cancer Center, 1515 Holcombe Blvd., Unit 1340, Houston, TX 77030-4009, USA. ${ }^{4}$ Department of Behavioral Science, MD Anderson Cancer Center, 1515 Holcombe Blvd. Unit 1340, Houston, TX 77030-4009, USA. ${ }^{5}$ Department of Pathology and Carolinas Cord Blood Banking Project, Duke University, 1430 N. Pavilion Bldg, Durham, NC 27705, USA. 'Department of Radiation Oncology, 139 Env Safety Bldg., Durham, NC 27710, USA. Department of Obstetrics and Gynecology, Division of Gynecologic Oncology, Department of Pathology Duke University, 226 B Wing LSRC Research Drive Durham, NC 27708, USA.

\section{Authors' contributions}

$\mathrm{CH}$ conceived of the study, designed the study directed the data collection, analysis and interpretation of the data, and drafted the manuscript. APM oversaw participant recruitment in the clinic, contributed to interpretation of the results and drafting the manuscript. JMS contributed to the study design, analysis, interpretation of the data and drafting the manuscript. MRF contributed to analysis and interpretation of the data. BC performed the statistical analysis. WDW contributed to the inception of the research hypothesis and aims. JK contributed to the logistics of data collection and interpretation of results. RLJ contributed to analysis and interpretation of the data. SKM helped conceive the study, contributed to the data interpretation and drafting the manuscript.

All authors read and approved the final manuscript.

\section{Competing interests}

The authors declare that they have no competing interests.

Received: 13 April 2010 Accepted: 21 January 2011 Published: 21 January 2011

\section{References}

1. Berry RJ, Li Z, Erickson JD, Li S, Moore CA, Wang H, Mulinare J, Zhao P, Wong LY, Gindler J, et al: Prevention of neural-tube defects with folic acid in China. China-U.S. Collaborative Project for Neural Tube Defect Prevention. The New England journal of medicine 1999, 341(20):1485-1490.

2. Czeizel $A E$, Dudas I: Prevention of the first occurence of neural-tube defects by periconceptional vitamin supplementation. The New England journal of medicine 1992, 327(26):1832-1835.

3. Effectiveness in Disease and Injury Prevention Use of Folic Acid for Prevention of Spina Bifida and Other Neural Tube Defects - 1983-1991. [http://www.cdc.gov/mmwr/preview/mmwrhtml/00014915.htm].

4. Prevention of neural tube defects: results of the Medical Research Council Vitamin Study. MRC Vitamin Study Research Group. Lancet 1991, 338(8760):131-137

5. Timmermans S, Jaddoe WW, Hofman A, Steegers-Theunissen RP, Steegers EA: Periconception folic acid supplementation, fetal growth and the risks of low birth weight and preterm birth: the Generation R Study. The British journal of nutrition 2009, 1-9.

6. (US) loM: Institute of Medicine. Dietary reference intakes from thiamin, riboflavin, niacin, vitamin B6, folate, vitamin B12, patothenic acid, biotin and choline. Washington, DC: National Academy Press; 1998.

7. CDC: Use of Supplements Containing Folic Acid Among Women of Childbearing Age - United States, 2007. Mmwr 2008, 57(1):5-8.

8. Finer LB, Henshaw SK: Disparities in rates of unintended pregnancy in the United States, 1994 and 2001. Perspectives on sexual and reproductive health 2006, 38(2):90-96.

9. US Food and Drug Administration: Food Standards: amendment of standards of identity for enriched grain products to require addition of folic acid. Federal Register 1996, 61:8781-8797.

10. Crane NT, Wilson DB, Cook DA, Lewis CJ, Yetley EA, Rader JI: Evaluating food fortification options: general principles revisited with folic acid. American journal of public health 1995, 85(5):660-666.

11. Lewis CJ, Crane NT, Wilson DB, Yetley EA: Estimated folate intakes: data updated to reflect food fortification, increased bioavailability, and dietary supplement use. Am J Clin Nutr 1999, 70(2):198-207.

12. Quinlivan EP, Gregory JF: Effect of food fortification on folic acid intake in the United States. Am J Clin Nutr 2003, 77(1):221-225.

13. Winkels RM, Brouwer IA, Siebelink $E$, Katan MB, Verhoef P: Bioavailability of food folates is $80 \%$ of that of folic acid. Am J Clin Nutr 2007, 85(2):465-473.

14. Caudill MA, Le T, Moonie SA, Esfahani ST, Cogger EA: Folate status in women of childbearing age residing in Southern California after folic acid fortification. J Am Coll Nutr 2001, 20(2 Suppl):129-134.

15. Jacques PF, Selhub J, Bostom AG, Wilson PW, Rosenberg $1 \mathrm{H}$ : The effect of folic acid fortification on plasma folate and total homocysteine concentrations. The New England journal of medicine 1999, 340(19):1449-1454.

16. Carmichael SL, Shaw GM, Yang W, Laurent C, Herring A, Royle MH, Canfield M: Correlates of intake of folic acid-containing supplements among pregnant women. American journal of obstetrics and gynecology 2006, 194(1):203-210

17. Forster DA, Wills G, Denning A, Bolger M: The use of folic acid and other vitamins before and during pregnancy in a group of women in Melbourne, Australia. Midwifery 2009, 25(2):134-146.

18. Nilsen RM, Vollset SE, Gjessing HK, Magnus P, Meltzer HM, Haugen M, Ueland PM: Patterns and predictors of folic acid supplement use among pregnant women: the Norwegian Mother and Child Cohort Study. The American journal of clinical nutrition 2006, 84(5):1134-1141.

19. Botto LD, Olney RS, Erickson JD: Vitamin supplements and the risk for congenital anomalies other than neural tube defects. Am J Med Genet $C$ Semin Med Genet 2004, 125C(1):12-21.

20. Goh Yl, Bollano E, Einarson TR, Koren G: Prenatal multivitamin supplementation and rates of congenital anomalies: a meta-analysis. J Obstet Gynaecol Can 2006, 28(8):680-689.

21. Wilson RD, Johnson JA, Wyatt P, Allen V, Gagnon A, Langlois S, Blight C, Audibert F, Desilets V, Brock JA, et al: Pre-conceptional vitamin/folic acid supplementation 2007: the use of folic acid in combination with a multivitamin supplement for the prevention of neural tube defects and other congenital anomalies. J Obstet Gynaecol Can 2007, 29(12):1003-1026.

22. Gabriel HE, Crott JW, Ghandour H, Dallal GE, Choi SW, Keyes MK, Jang H, Liu Z, Nadeau M, Johnston A, et al: Chronic cigarette smoking is associated with diminished folate status, altered folate form distribution, and increased genetic damage in the buccal mucosa of healthy adults. Am J Clin Nutr 2006, 83(4):835-841.

23. Yang QH, Carter HK, Mulinare J, Berry RJ, Friedman JM, Erickson JD: Raceethnicity differences in folic acid intake in women of childbearing age in the United States after folic acid fortification: findings from the National Health and Nutrition Examination Survey, 2001-2002. Am J Clin Nutr 2007, 85(5):1409-1416.

24. McGuire M, Cleary B, Sahm L, Murphy DJ: Prevalence and predictors of periconceptional folic acid uptake-prospective cohort study in an Irish urban obstetric population. Human reproduction (Oxford, England) 25(2):535-543.

25. North Carolina Reported Pregnancies - 2006. North Carolina Dept. of Health and Human Services, State Center for Health Statistics; 2006.

26. Ulrich CM: Folate and cancer prevention: a closer look at a complex picture. Am J Clin Nutr 2007, 86(2):271-273. 
27. Czeizel $A E$, Metneki J, Dudas I: Higher rate of multiple births after periconceptional vitamin supplementation. The New England journal of medicine 1994, 330(23):1687-1688

28. Ericson A, Kallen B, Aberg A: Use of multivitamins and folic acid in early pregnancy and multiple births in Sweden. Twin Res 2001, 4(2):63-66.

29. Vollset SE, Gjessing HK, Tandberg A, Ronning T, Irgens LM, Baste V, Nilsen RM, Daltveit AK: Folate supplementation and twin pregnancies. Epidemiology 2005, 16(2):201-205

30. Lucock M, Yates Z: Folic acid - vitamin and panacea or genetic time bomb? Nature reviews 2005, 6(3):235-240.

31. Munoz-Moran E, Dieguez-Lucena JL, Fernandez-Arcas N, Peran-Mesa S, Reyes-Engel A: Genetic selection and folate intake during pregnancy. Lancet 1998, 352(9134):1120-1121.

32. Gilbody S, Lewis S, Lightfoot T: Methylenetetrahydrofolate reductase (MTHFR) genetic polymorphisms and psychiatric disorders: a HuGE review. American journal of epidemiology 2007, 165(1):1-13.

33. Lewis SJ, Lawlor DA, Davey Smith G, Araya R, Timpson N, Day IN, Ebrahim S: The thermolabile variant of MTHFR is associated with depression in the British Women's Heart and Health Study and a metaanalysis. Molecular psychiatry 2006, 11(4):352-360.

34. Muntjewerff J, Blom HJ: Aberrant folate status in schizophrenic patients: what is the evidence? Progress in neuro-psychopharmacology \& biological psychiatry 2005, 29(7):1133-1139.

35. Haberg SE, London SJ, Stigum H, Nafstad P, Nystad W: Folic acid supplements in pregnancy and early childhood respiratory health. Archives of disease in childhood 2009, 94(3):180-184

36. Steegers-Theunissen RP, Obermann-Borst SA, Kremer D, Lindemans J Siebel C, Steegers EA, Slagboom PE, Heijmans BT: Periconceptional Maternal Folic Acid Use of 400 microg per Day Is Related to Increased Methylation of the IGF2 Gene in the Very Young Child. PLoS One 2009, 4(11):e7845.

37. DeBaun MR, Niemitz EL, McNeil DE, Brandenburg SA, Lee MP, Feinberg AP. Epigenetic alterations of $\mathrm{H} 19$ and LIT1 distinguish patients with Beckwith-Wiedemann syndrome with cancer and birth defects. American journal of human genetics 2002, 70(3):604-611.

38. Cui H, Cruz-Correa M, Giardiello FM, Hutcheon DF, Kafonek DR, Brandenburg S, Wu Y, He X, Powe NR, Feinberg AP: Loss of IGF2 imprinting: a potential marker of colorectal cancer risk. Science (New York, NY 2003, 299(5613):1753-1755.

39. D'Angelo D, Williams L, Morrow B, Cox S, Harris N, Harrison L, Posner SF, Hood JR, Zapata L: Preconception and interconception health status of women who recently gave birth to a live-born infant-Pregnancy Risk Assessment Monitoring System (PRAMS), United States, 26 reporting areas, 2004. MMWR Surveill Summ 2007, 56(10):1-35.

40. Jasti S, Siega-Riz AM, Cogswell ME, Hartzema AG, Bentley ME: Pill count adherence to prenatal multivitamin/mineral supplement use among low-income women. J Nutr 2005, 135(5):1093-1101.

41. Bodnar LM, Tang G, Ness RB, Harger G, Roberts JM: Periconceptional multivitamin use reduces the risk of preeclampsia. American journal of epidemiology 2006, 164(5):470-477.

42. Green-Raleigh K, Lawrence JM, Chen H, Devine O, Prue C: Pregnancy planning status and health behaviors among nonpregnant women in a California managed health care organization. Perspectives on sexual and reproductive health 2005, 37(4):179-183.

43. Radimer K, Bindewald B, Hughes J, Ervin B, Swanson C, Picciano MF: Dietary supplement use by US adults: data from the National Health and Nutrition Examination Survey, 1999-2000. American journal of epidemiology 2004, 160(4):339-349.

44. de Jong-Van den Berg LT, Hernandez-Diaz S, Werler MM, Louik C Mitchell AA: Trends and predictors of folic acid awareness and periconceptional use in pregnant women. American journal of obstetrics and gynecology 2005, 192(1):121-128.

45. Bentley TG, Willett WC, Weinstein MC, Kuntz KM: Population-level changes in folate intake by age, gender, and race/ethnicity after folic acid fortification. American journal of public health 2006, 96(11):2040-2047.

46. Behavioral Risk Factor Surveillance System Survey Data. U.S. Department of Health and Human Services, Centers for Disease Control and Prevention; 2007.

47. McDonnell R, Johnson Z, Doyle A, Sayers G: Determinants of folic acid knowledge and use among antenatal women. Journal of public health medicine 1999, 21(2):145-149.
48. Braekke K, Staff AC: Periconceptional use of folic acid supplements in Oslo. Acta obstetricia et gynecologica Scandinavica 2003, 82(7):620-627.

\section{Pre-publication history}

The pre-publication history for this paper can be accessed here: http://www.biomedcentral.com/1471-2458/11/46/prepub

doi:10.1186/1471-2458-11-46

Cite this article as: Hoyo et al:: Folic acid supplementation before and during pregnancy in the Newborn Epigenetics STudy (NEST). BMC Public Health 2011 11:46.

\section{Submit your next manuscript to BioMed Central and take full advantage of:}

- Convenient online submission

- Thorough peer review

- No space constraints or color figure charges

- Immediate publication on acceptance

- Inclusion in PubMed, CAS, Scopus and Google Scholar

- Research which is freely available for redistribution

Submit your manuscript at www biomedcentral.com/submit
C Biomed Central 